\title{
Expansive learning in a change laboratory intervention for teachers
}

\author{
Dennis Augustsson ${ }^{1}$ iD
}

Accepted: 25 September 2020 / Published online: 15 January 2021

(c) The Author(s) 2021

\begin{abstract}
The theory of Expansive learning and the change laboratory (CL) methodology has been developed and applied in many studies on workplace learning and educational change. There are fewer studies made on small-scale interventions, exploring the longitudinal development of expansive learning in an educational change effort. This article examines a CL intervention performed in an upper secondary school in Sweden, with a small group of teachers engaged in a participatory design project. By identifying and analysing the relationship of the seven learning actions posited by the theory of expansive learning, the aim was to contribute to the discussion of the CL methodology and the empirical usability of the theory. The results showed that the seven expansive learning actions functioned as analytical tools to map the teachers learning and development, but the analysis also showed many deviations, disruptions and occurrence of practical actions of design in the process. This challenge the notions of cyclicity and ascension in the theory of expansive learning. Cyclicity might be desirable but not necessary for expansive learning which questions the need to first grasp the problem at a conceptual level before generating concrete solutions. The Findings in this study suggests the opposite; that the entanglement and parallel movement between the abstract and the concrete was a driving force for the teachers expansive learning and the design of new curricular units.
\end{abstract}

Keywords Educational change $\cdot$ Activity theory $\cdot$ Change laboratory $\cdot$ Design processes $\cdot$ Teaching $\cdot$ Professional development

\section{Introduction}

The theory of expansive learning and the Change Laboratory (CL) methodology has been developed and applied in many studies since its introduction by Yrjö Engeström in 1987 (Engeström 2015; Engeström and Sannino 2010). As an

Dennis Augustsson

dennis.augustsson@hv.se

1 University West, 46186 Trollhättan, Sweden 
interventionist approach to workplace learning and educational change, it aims to explain and guide collective, transformative processes as part of complex activity systems (Engeström 2008). In 2013, Yrjö Engeström, Juhana Rantavuori and Hannele Kerosuo examined the empirical usability and methodological rigor afforded by the theory (Engeström et al. 2013). They developed a method to identify and analyse learning actions over time in a longitudinal design to explore and demonstrate empirical evidence of expansive learning in CL interventions. Following the citation index since the publication, two studies have adopted the method in its original form (Englund 2018; Bal et al. 2018). All three studies (including Engeström et al. 2013) claimed an overall concurrence with the general model of expansive learning but also showed particular traits in the appearance, frequency and cyclicity of learning actions. All three interventions claimed to be successful in terms of leading to change and improvement, being 'an activity-producing activity' (Engeström 2015 , p. 99, italics in the original). As the results are promising, there is a need for more studies to be able to compare and draw general conclusions. While there are many studies using activity theory and expansive learning in the study of educational change (Botha 2017; Sannino 2008; Teräs and Lasonen 2013; Engeström et al. 2002; Yamazumi 2008), few of these have been conducted on small-scale interventions, exploring the longitudinal development of expansive learning by analysing participants' discourse in the series of intervention sessions. This is needed and important to demonstrate evidence of expansive learning and the usability of CL interventions for educational change.

\section{Purpose and research questions}

This article examines a CL intervention in an upper secondary school in Sweden, performed as a professional development activity for teachers. By using the method of analysis, developed by Engeström et al. (2013), the aim is to further contribute to the discussion of its merits and affordance. The study explores how the seven learning actions posited by the theory of Expansive Learning and CL methodology, can contribute to the understanding of teachers' learning process by answering the following research questions:

1. Which learning actions posited by the theory of expansive learning can be identified in the CL intervention?

2. What is the relationship between different learning actions in terms of cyclicity and linearity over the whole intervention and at the session level?

This article provides a description of the performed CL to contextualize the analysis of the participants' discourse, but the analytical focus is set on the identification and relationship of expansive learning actions and non-expansive learning actions as well as the cyclicity and evolution of expansive learning on the level of the whole intervention and at the session level. 
In the next section a description of the theoretical framework is presented, followed by an account of the performed CL to provide a context for the analysis of participants' learning actions. Then a description of the data and method for analysis is presented, followed by the results of the analysis to answer the research questions.

\section{Theoretical framework}

The Change Laboratory is a research intervention method, that builds on Cultural Historical Activity Theory (CHAT) and its core concept of expansive learning (Engeström 2015). CHAT explains human activity as an object-oriented, culturally mediated system with six interconnected components: subject, object, tools, community, rules and division of labour. Expansive learning is understood as a collective process in which participants, through learning actions, change and create new activities by going beyond the already known and relatively stable practices within the activity system. It's a process of learning what is not yet there (Sannino et al. 2016). The process is intended to reveal contradictions and inner conflicts of the activity system and to generate a zone of proximal development in which new concepts and practices can emerge. The concept of learning actions is developed from Leont'evs distinction between the levels of operations, actions and activities (Leont'ev 1978). In CHAT, activity, formulated as a systemic and collective formation directed toward an object and motive, is realized by the means of actions. The object of an activity is not always clear or articulated by participants, but actions are performed, individually or collectively to accomplish conscious intentional goals directed towards the object of the activity. Actions are comprised by operationsoften unconscious, routine actions using available tools. (Engeström 2015). The activity system is often described as the unit of analysis in CHAT, but it's through the actions of participants that the system becomes tangible and explorable. The epistemological principle of ascending from the abstract to the concrete guides the understanding of expansive learning (Sannino and Engeström 2017). The principle is developed by V.V. Davydov, building on dialectical materialism (Davydov 1990). He uses the concept of theoretical-genetic thinking to describe the dialectical movement between the abstract and the concrete in the formation of concepts. To ascend from the abstract to the concrete, you need to analyse the origin and development of the concepts within a system to grasp the essential meaning before you can analyse and transform the particular phenomena at hand. Davydov conducted experiments with 1st grade students where mathematical concepts were introduced and experimented with, before the introduction of numbers. By using general representations (letters) to describe and understand general concepts of mathematics, students developed a theoretical understanding of the principles before using them, making it easier to understand and use more complex equations. Findings suggested that this was possible with seven-year-old students, but also that it equipped them with tools to overcome the gap between 'arithmetic' and 'algebra' that is typical of traditional teaching (Davydov 1990). In this example, the theoretical genetic thinking is bound by a very specific activity, that of learning pre-defined, basic mathematical concepts. In a CL intervention, the goal is to analyse and change a complex activity system 
without a predefined model. The theoretical generalizations from these processes serve as tools for identifying problems and generate a zone of proximal development in which you can develop a solution (Virkkunen and Schaupp 2011). This process has a transformative character and is the foundation for the notion of expansive learning (Engeström 2015). The result of modelling theoretical generalizations into comprehensible concepts carrying both contradictions and possible solutions in CL methodology is called a germ cell. A germ cell can sometimes be an abstract concept like responsibility in a surgical unit intervention or integration in a home care unit intervention (Sannino and Engeström 2017). But it can also be the concrete embodiment of the problem incorporating possible solutions, like standing up from a chair, in the home care practice intervention for elderly adults (Engeström et al. 2012). The boundary of a germ cell is therefore not a fixed form of representation or a finalized stage in the process of ascending from the abstract to the concrete, but a stage that, can capture the problem in a simple idea that can be transformed and expanded into new forms of practice.

The metaphor of ascension suggests a linearity in the process and the theory of expansive learning proposes seven steps or learning actions to achieve this: questioning, analysing, modelling, examining, implementing, reflecting, and consolidating. These steps form an ideal cycle of expansive learning as depicted in Fig. 1. Ascensions are not linear but spiralling and a CL is normally designed as one overarching cycle of these steps.

CLs are designed by the interventionists to facilitate these steps in a series of sessions with a pre-planned script to promote desired learning actions, using the Vygotskian principal of double stimulation (Vygotsky 1987; Sannino 2015). The first

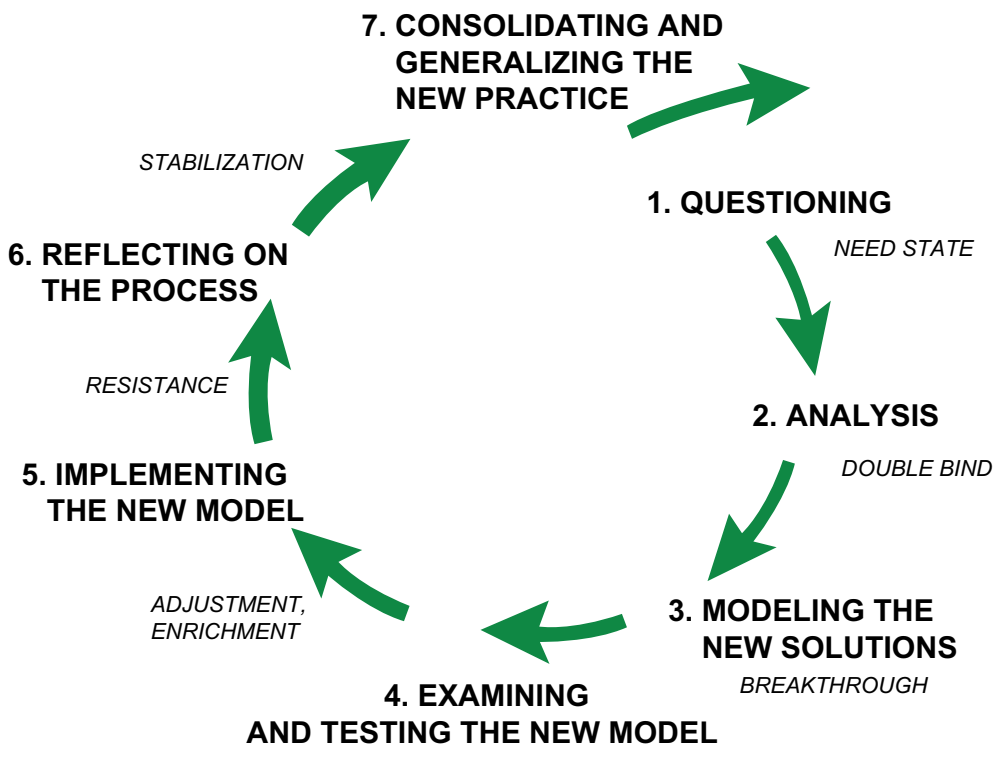

Fig. 1 Sequence of learning actions in an expansive learning cycle (adapted from Engeström and Sannino 2010, p. 8) 
stimulus is created by the experiences of contradictions and tensions in the current practice or a task for the participants directing the process. The second stimulus is brought about by given signs or artefacts that help to analyse and organize the activity promoting change and innovation. In a CL, these artefacts are called mirror materials and usually consist of graphic representations of the activity systems and video recorded material from ethnographical research done beforehand (Engeström et al. 2013). The theory posits four phases of resistance and contradictions. Primary contradictions experienced will be aggravated and manifested as secondary contradictions in the steps of analysing and modelling. Tertiary contradictions will be manifest in the step of implementation and quaternary contradictions will emerge when the consolidated new activity meets its neighbouring activity systems (Engeström et al. 2013).

In many studies the ideal cycle of expansive learning is interrupted by non-expansive learning actions and deviations from the interventionist script:

The theory of expansive learning emphasizes that the ideal-typical sequence of actions in a cycle is not to be found in pure form in practice; there are odd combinations, breaks, digressions and iterative loops. If this is the case, when are we entitled to speak of the appearance of a cycle? (Engeström et al. 2013, p 86).

Deviations from the cycle of expansive learning and the interventionist script can be interpreted as signs of volition and agency in the process. Indeed, it can become an argument for the most expansive movement suggesting that breaking free from the linearity and the script is not just possible, but a necessary action for true expansive learning:

The very process is punctuated by deviations which open up space for learner agency and creation of truly new solutions and concepts. The reception, negotiation and expansive bridging of these deviations are exciting challenges for further research. (Engeström et al. 2013, p 103).

If deviations from the cyclicity in the process and intentions from the interventionists can be signs of expansive learning it becomes relevant to ask if cyclicity and the linear movement of ascension is a sufficient way to describe expansive learning.

\section{Context: The setting and the intervention}

The following section is an account of the background, setting, and a brief description of the CL process to contextualize the analysis of learning actions conducted in this article.

The possibilities and visions for educational change have been expressed in policy documents with categories like 21st century skills and lifelong learning (European commission 2013; Trilling and Fadel 2009; UNESCO 2011). In these policies, digital literacy and media literacy are combined with concepts of creativity and innovation, social and cross-cultural interaction, collaboration, critical thinking, 
adaptability, communication, and problem solving. To meet these demands a small, participatory design project was conducted in 2016 as a professional development activity between two upper secondary schools in the USA and Sweden. The design challenge was to create an international collaboration on Ocean Literacy, using video production to produce and communicate knowledge. The development of new curricular units took place in a design process where the researcher, four teachers, and their students collaborated to plan, implement, and evaluate video production as a tool for learning. For a more detailed description of the design process, see (Augustsson 2018).

A workshop using CHAT was conducted to analyse and evaluate the first iteration of the design process together with teachers from the Swedish school in which participants expressed tensions and contradictions at systemic levels in the design process. A CL intervention was proposed by the researcher and accepted by the teachers to address issues on video production as a curricular activity on a more general level in the search for a germ cell, and to feed the design process for the international collaboration.

The adoption of a CL intervention to respond to the challenges in an ongoing design process is not a traditional point of entry for the CL methodology and the timetable for the sessions spread them out over eighteen months. The CL was designed by adding five sessions to the CHAT workshop which initially was planned as a single session to evaluate the first iteration of the collaboration. To follow the whole process, the last session was planned and conducted after the implementation of the new designs.

A summary of the sessions and their purposes can be found in Table 1. During the process there were $2-3$ teachers and a researcher participating. The small team allowed for an openness in the structure, and participating teachers were given the freedom to pursue issues most relevant to them. The script for the $\mathrm{CL}$ was focused on general modelling but the participants' need for concrete solutions created a process of both general modelling and concrete design of curricular units within the sessions.

In Session 1, the participating teachers were presented with a blank representation of the activity system model which was filled with content using post-it notes and discussions during the session. This stimulus made the tensions and contradictions visible and tangible, built on participants' own analysis of their activity.

Participating teachers could map several tensions and contradictions within the activity and the most urgent ones were the contradictions between the object of cross curricular activities, collaborative media production, and the curricular demand on specific learning outcomes and individual assessments (Arrow B in Fig. 2).

In Session 2, the researcher presented a four-field model (Fig. 3) of what were perceived to be conflicts of motives and a Zone of Proximal Development (Sannino and Engeström 2017). Promoting learning activities with a focus on social skills, collaboration, and media literacy, described as twenty first century skills (Trilling and Fadel 2009), was in conflict with the need to focus on specific subject matters, easy-to-measure outcomes, and individual assessment. These conflicts were represented on two axes where traditional practices were placed in the bottom left corner and a Zone of Proximal Development towards learning activities promoting twenty 


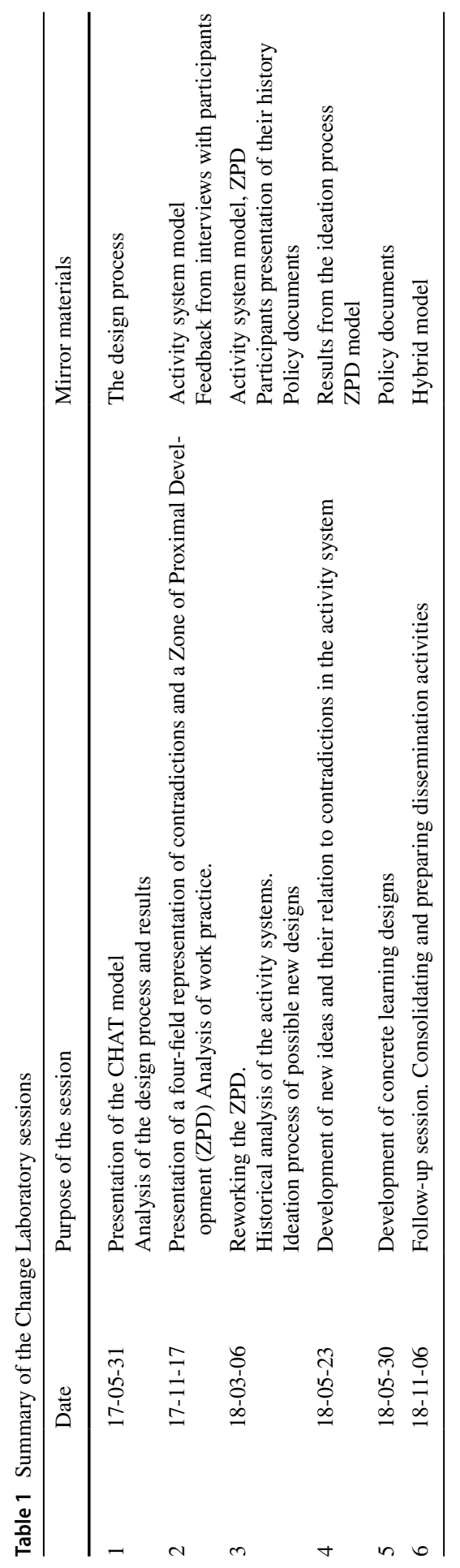




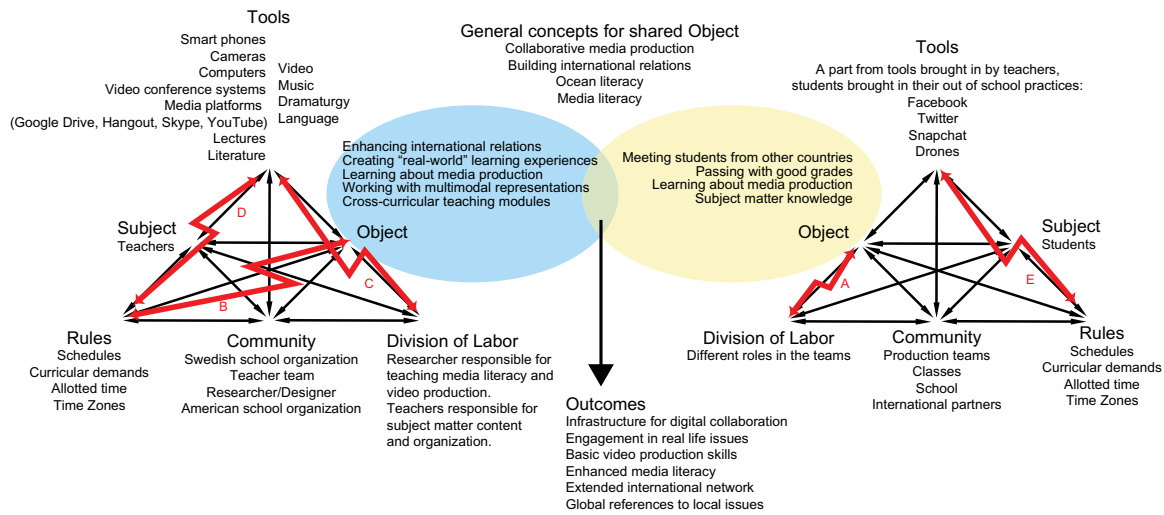

Fig. 2 The result of the CHAT analysis done by teachers and the researcher (Author 2018)

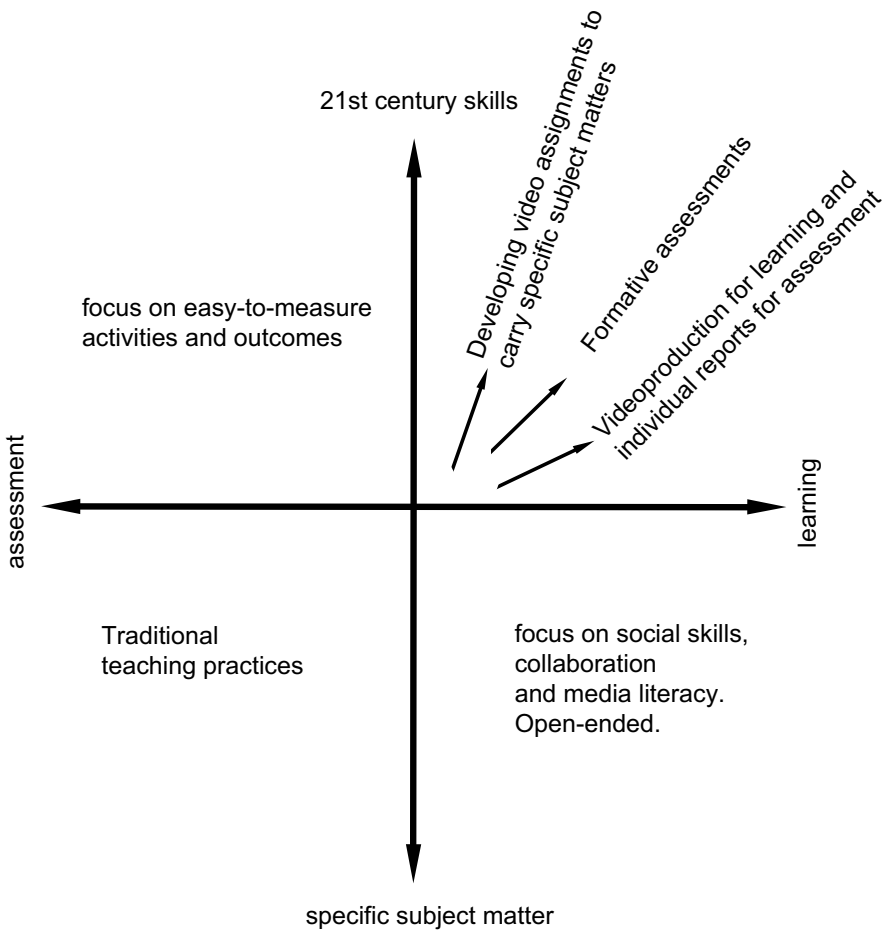

Fig. 3 The four-field model from Session 2

first century skills in the upper right corner. Possible spearheads into this ZPD were made visible, articulated, and discussed.

In Session 3, the model was examined and remodelled together with a historical analysis of the development of curricular demands and the teachers' personal journey 
to their present situation. One of the spearheads, 'Video production for learning and individual reports for assessment', was tried in an ideation process for new curricular units, conceptualized as 'Hybrid practices'.

In Sessions 4 and 5, concrete design activities were mixed with analysis on a general level. The abstract movie was a curricular unit that was used frequently to describe the concept of different hybrid forms of activity. In science class, students performed experiments documented with video that was edited to an audio-visual abstract as a complement to an individual written report. From that idea several new ideas for tasks involving video production emerged. It was a concrete curricular unit, developed in the process that could solve the issues of the contradictory demands. The idea of hybridity-to mix different forms of activity and representation-explained the concept, while the abstract movie as a task embodied the concept in a simple, concrete way. Its explanatory and transformational power made it a possible springboard for the use of video production in more instructional designs.

In Session 6, conducted six months later, the implemented learning designs were evaluated and a dissemination activity for a national conference on media literacy was planned as part of the consolidation of the new practices. But even in this session, new ideas were discussed and examined. An inventory of the evolution of recently implemented learning sequences was done, showing an increase in learning tasks with video production from one subject and six videos made in the first iteration of the design, in 2016, to four subjects and 64 videos produced in the courses at the time of the evaluation, in 2018. The teachers had held a workshop for the rest of the organization and two more teachers were involved in the process. Even if these changes were not visible on an organizational level, changes had occurred in both socio-material and temporal space and were proved to be a stable new practice that continued to develop.

\section{Methods}

In this section I will present the data collection and the method of analysis used by Engeström et al. (2013) with a discussion on the challenges when adapted to the CL intervention presented in this article.

\section{Data collection}

The raw data for the analysis consists of video recordings of the six Change Laboratory sessions. The total length of the recorded material was $418 \mathrm{~min}$. The length of the sessions varied between 57 and $96 \mathrm{~min}$. The introduction to Session 4 was not captured on video and left out of the analysis. The video material was transcribed, verbatim, by the researcher.

\section{Analysis}

Following the method devised by Engeström et al. (2013), the first step of the analysis is to identify learning actions and the frequency of these in the CL process. 
Learning actions were first identified in the material by discerning episodes based on their substantive contents. Analysis of the conversations within each episode was performed to specify actions and formulate a preliminary description of these actions. Using the framework of the seven expansive learning actions, the epistemic functions of the actions were determined and non-expansive actions were identified. Off topic contents, social conversation and technicalities were separated and not included in the detailed analysis (11\% of the material). The criteria for identifying the different expansive learning actions are summarized below:

1. Questioning - a critique or rejection of aspects of current practice or suggested changes.

2. Analysing - action taken to explore causes and to explain the problematic situation.

3. Modelling-ideation and construction of an explicit, simplified model that explains and offers a solution to the problematic situation.

4. Examining-running, operating and experimenting with the model in order to fully grasp its dynamics, potentials, and limitations.

5. Implementing - preparation and practical application of the model, enrichments, and conceptual extensions.

6. Reflecting - evaluation and reflection on the process of expansive learning.

7. Consolidating - generalizing the outcomes and consolidating and them into a new stable form of practice.

Learning actions, that are not categorized in these groups and not part of the expansive process, are categorized as non-expansive learning actions. The CL was initiated to address systemic tensions and contradictions experienced in the enactment of the international collaboration using media production as a means for learning and representation. The script for the CL was focused on theoretical modelling, but the participants' need for continuing the design of concrete solutions created a parallel process within the sessions of theoretical modelling and concrete design of curricular units, not one following the other. This challenged the criterion and boundaries of some of the expansive learning actions. Modelling, examination, and implementation share the same traits when ideas are developed and tested in the workplace during the process. Ideation, experimentation, practical application, and enrichment of new designs could fit in any of the three categories. In the analysis of learning actions there was a need to distinguish actions directed at theoretical modelling from acts of designing concrete solutions. This was done by creating new subtypes of learning actions in the next step of the analysis. The need for subtypes in the analysis is also connected to the epistemological principles of the theory of expansive learning:

It is also likely that the proposed expansive learning actions are internally heterogeneous. In fact, the theory already names two subtypes present in the act of analysis, namely historical-genetic analysis and actual-empirical analysis. The identification of subtypes within the expansive learning actions may significantly increase the empirical usability of the theory. (Engeström et al. 2013, p. 86). 
Questioning and analysing are the two learning actions that are most underpinned by the principles from developmental psychology and activity theory and distinguish the cycle of expansive learning from that of other participatory design processes. Engeström et al. (ibid) identified three subcategories of questioning: Q1-Challenging participants into questioning Q2 - Criticizing existing practice and Q3-Questioning the proposed development. Acts of analysis were the dominant category in their study and five subtypes were identified: A1-Articulating needs and ideas, A2-Historical analysis, A3-Articulating problems or challenges A4-Identifying contradictions, and A5-Weighing alternative solutions. The suggested subtypes in these categories reflect the different forms of systemic contradictions and analytical tools provided by the theory and could probably be used as generic categories for all CL interventions, showing the significant epistemic differences within expansive learning actions. The subtypes in the other categories were less connected to the epistemological principles of the theory and seem more situated and descriptive of the specific intervention.

For modelling, Engeström et al. (ibid.) identified five subtypes: M1-Sketching the initial idea of a model, M2-Exploiting existing models, M3-Naming and defining the model, M4-Fixing the model in material or graphic form and M5Varying and adapting the model. These subtypes were used to describe theoretical modelling and are quite specific in form and suggest a cyclicity in the modelling process, but the design of concrete curricular units needed other categories. The same need for specific, situated subtypes was identified in the study of Bal et al. (2018). Engeström et al. (ibid.) identified two subtypes of examining: E1-Discussing the model critically and E2-Enriching the model. These are two broad categories connected to the process of theoretical modelling. Here there was a challenge to define the differences between the other learning actions. The category of enriching the model is not easily distinguished from varying and adapting the model (M5), and discussing it critically could be a way of weighing alternative solutions (A5) or even questioning the proposed development (Q3). Experimenting with a model or prototype is a combination of analytical and modelling acts. Since implementation was not part of the intervention in 2013, Engeström et al. found two subtypes: I1-Demonstrating implementation and I2-Preparing implementation. They proposed two other subtypes for an intervention where implementation was followed through: I3-Actual use of the new model and I4-Reporting on the use of the new model. This raises questions about the boundaries of the interventions. The actual use of a model can never reach inside the CL intervention in any other form than the reporting and analysis of these actions with the current structure of the CL method. There were no acts of reflection or consolidation in their study and therefore no sub-categories were identified or discussed. Even if the boundaries between different subtypes can be blurry and the need for new categories for concrete curricular designs emerged in this study, effort was made to keep the original categories, and all learning actions were categorized as either part of the concrete design process or the process of theoretical modelling. The whole process of identification was done, iteratively, three times for a finalized categorization used for counting the frequency of expansive learning actions and further analysis. The categorization was however not verified by a second analyst/researcher. 
The last step in the analysis was to explore the characteristics of possible cyclicity of the expansive learning actions in the CL process. A comparison was made between the ideal cycle of expansive learning and the evolution of learning actions on the level of the whole CL process, but also on the level of each session, to find what kind of smaller scale cyclicity there might be within the overall process. For this, the criterion of at least four expansive learning actions in a meaningful order to identify an expansive cyclicity was used (Engeström et al. 2013).

\section{Results}

Table 2 summarizes the appearances and frequency of the learning actions.

\section{Expansive learning actions}

The first research question posed for this study concerned the identification of learning actions in the CL intervention. All seven learning actions proposed in the theory of expansive learning were identified. Most frequent were acts of analysis which occurred 106 times, followed by acts of modelling (49 times) and examining (25 times). Actions related to implementing occurred 21 times and questioning 20 times. The acts of consolidating and reflecting on the process were the least frequent ones, occurring eight and six times, respectively. Identification of all expansive learning actions suggests a full expansive learning cycle, but the different actions were

Table 2 Types and frequency of expansive and non-expansive learning actions in the Change Laboratory

\begin{tabular}{|c|c|c|c|c|c|c|c|}
\hline & $\mathrm{S} 1$ & S2 & S3 & $\mathrm{S} 4$ & S5 & S6 & Total \\
\hline \multicolumn{8}{|l|}{ Expansive learning actions } \\
\hline Questioning & 8 & 3 & 6 & 1 & 2 & 0 & 20 \\
\hline Analysing & 23 & 22 & 28 & 13 & 12 & 8 & 106 \\
\hline Modelling & 7 & 10 & 10 & 9 & 9 & 4 & 49 \\
\hline Examining & 0 & 4 & 7 & 3 & 8 & 3 & 25 \\
\hline Implementing & 3 & 2 & 2 & 1 & 1 & 12 & 21 \\
\hline Reflecting on the process & 1 & 1 & 1 & 0 & 0 & 3 & 6 \\
\hline Consolidating & 0 & 0 & 0 & 0 & 0 & 8 & 8 \\
\hline Total & 42 & 42 & 54 & 27 & 32 & 38 & 235 \\
\hline \multicolumn{8}{|c|}{ Non-expansive learning actions } \\
\hline Informing & 4 & 0 & 4 & 1 & 2 & 3 & 14 \\
\hline Clarifying & 1 & 0 & 0 & 2 & 0 & 4 & 7 \\
\hline Summarizing & 1 & 0 & 1 & 0 & 0 & 0 & 2 \\
\hline Planning & 0 & 2 & 0 & 1 & 1 & 0 & 4 \\
\hline Isolated episode & 1 & 1 & 1 & 1 & 1 & 1 & 6 \\
\hline TOTAL & 7 & 3 & 6 & 5 & 4 & 8 & 33 \\
\hline All learning actions & $\mathrm{S} 1$ & $\mathrm{~S} 2$ & S3 & $\mathrm{S} 4$ & S5 & S6 & \\
\hline TOTAL & 49 & 45 & 60 & 32 & 36 & 46 & 268 \\
\hline
\end{tabular}


dispersed, not one following the other, intersected with non-expansive learning actions. The same observation was made in the study by Engeström et al. claiming that this 'challenges the purist notion of expansive learning' (Engeström et al. 2013, p. 92). This will be discussed in the section on cyclicity below.

\section{Non-expansive learning actions}

Non-expansive learning actions are actions of finite episodes that do not directly lead to other actions or carry potential for dialectical development in the process. They do not trigger any other learning actions. Thirty-three of these actions were identified in the data. The subtypes of informing, clarifying and summarizing identified by Engeström et al. were used and four actions dedicated to practical planning were identified as a new subtype. The relational aspect of learning actions to other learning actions is an important factor to identify them as expansive. As the dialectical movement between actions is critical for expansive learning, actions that have the potential and relevance to become expansive learning actions, but are left as isolated episodes in the process, must be considered non-expansive. An example in the data was a discussion of the new legislation for personal data registration and storage (GDPR) in Session 4 that could have had bearing on both theoretical modelling and concrete designs but didn't lead to any other learning actions. It remained an isolated episode in relation to the rest of the process. In the data, six such episodes were identified and categorized as isolated episodes, a subtype of non-expansive learning actions.

\section{Subtypes of expansive learning}

The identification and categorization of subtypes of learning actions are important for analysing the appearance and frequency of actions connected to the different epistemic functions, especially in the category of analysis. In this study it was also important to distinguish between theoretical modelling and concrete design. The different subtypes and their frequency are summarized in Table 3. Throughout the CL sessions, previous designs and new designs were used for evaluation and analysis. Only eight of the identified actions of modelling were focused on the theoretical conceptualization, compared to 41 learning actions focused on concrete designs. Apart from in Session 4, they were not planned or articulated as mirror material by the researcher but became important tools for grasping the theoretical conceptualization throughout the process.

This deviation is an example of what Engeström et al. (2013) identified as a space for agency and volition in which the dialectic movement between different motives of instruction and learning can be the vehicle for novel ideas and expansion (Engeström et al. 2013). When implemented, curricular units were used to discuss the general model. They were coded as 'analysing implemented curricular units' - a subtype for analysing. When connected to the development of specific designs they were coded as 'evaluation of implemented curricular units' - a subtype 
Table 3 Subtypes of expansive and non-expansive learning actions and their frequency

Subtypes of expansive and non-expansive learning actions

Questioning

Q1: Challenging participants into questioning 3

Q2: Criticizing existing practice 12

Q3: Questioning the proposed development 5

Analysing

A1: Articulating needs and ideas

A2: Historical analysis $\quad 8$

A3: Articulating problems or challenges $\quad 28$

A4: Identifying contradictions 4

A5: Weighing alternative solutions $\quad 13$

A6: Analysing implemented curricular units 12

A7: Interpretation of rules and policies $\quad 12$

Modelling

M1: Sketching the initial idea of a model 1

M2: Naming and defining the model 2

M3: Fixing the model in material or graphic from 1

M4: Varying and adapting the model 4

M5: Ideation for concrete curricular units $\quad 16$

M6: Ideation for redesign of implemented curricular units 25

Examining

E1: Discussing the model critically $\quad 7$

E2: Enriching the model $\quad 4$

E3: Analysing not yet implemented curricular units $\quad 14$

Implementing

I1: Reporting on the use of designed curricular units $\quad 7$

I2: Evaluation of implemented curricular units $\quad 14$

Reflecting on the process

R1: Reflections on activities in the process $\quad 2$

R2: Reflections on personal professional development 4

Consolidating and generalizing

C1: Articulating and summarizing outcomes 4

C2: Discussing ideas for generalisations $\quad 2$

C3: Preparing dissemination activities $\quad 2$

Non expansive learning actions

N1: Informing $\quad 14$

N2: Summarizing $\quad 2$

N3: Clarifying $\quad 7$

N4: Isolated episode $\quad 6$

N5: Planning for implementation of curricular units 4 
of implementing. The parallel process suggests that dialectical movement between actions towards the abstract and actions towards the concrete shaped the form of both.

The interpretation of policy documents and curricular demands was a central focal point for the process and made up a subtype of its own. Ideation of concrete curricular units were coded as a subtype of modelling as well as redesign of performed learning sequences. Actions to examine ideas of concrete designs were coded as a subtype of examining: 'analysing not yet implemented curricular units'. The subtypes of implementation identified were reporting and evaluation of implemented curricular units. The aim of the CL was to create a germ cell or theoretical model for the development of new concrete curricular units. The implementation of the model took the shape of the enactment of these concrete curricular units. The entanglement of theoretical conceptualization and concrete design will be discussed further in the section of cyclicity below. Two subtypes of reflections on the process were identified by the participants: 'reflections on activities in the process' and 'reflections on personal professional development'. The last session was dedicated to generalizing and consolidating. As part of this process, ideas for a dissemination were developed. From the learning actions performed here, three subtypes were identified: 'articulating and summarizing outcomes', 'formulating ideas for generalizations', and 'preparing dissemination activities'.

\section{Cyclicity in the learning process}

The second research question posed for this study concerned the relationship between different learning actions in terms of cyclicity and linearity over the whole intervention and at the session level. To examine the cyclicity of the entire CL process a diagram of the evolution of expansive learning actions was created (Fig. 4). The diagram with all learning actions shows how analysis dominated the process with a peak in Session 3, and then fading as the process continued. The acts of questioning follow the curve of analysis. When acts of questioning are frequent, so are acts of analysis, suggesting that these two actions trigger each other in the process.

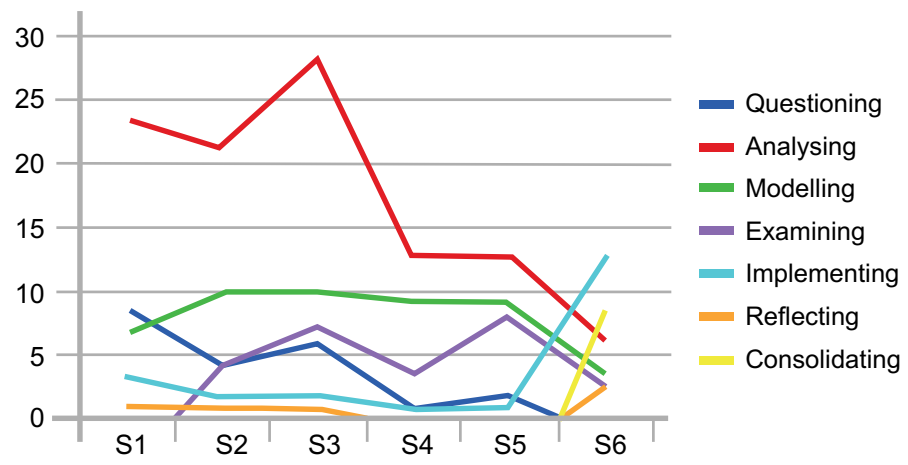

Fig. 4 Evolution of frequency of different expansive learning actions over the course of the CL sessions 
The curve of modelling is more or less static from Session 2 to Session 5, a deviation from the ideal cycle of expansive learning but examining rises throughout the process to peak in Session 5. One action of reflection is present in the first three sessions, prompted by the researcher but non-existent in Sessions 4 and 5, which were designated for modelling and concrete design. In Session 6, the learning actions of implementing, reflecting and consolidation rise steeply, while other actions decline, in line with the intended script. On a general level this follows the sequence of the theoretical model of the expansive learning cycle.

Since the modelling, implementation, and examination of concrete curricular units were part of the process from the beginning, there is a need to extract these learning actions to examine the process of general modelling. Two new diagrams were created: one representing the learning actions focused on general analysis, modelling, and the creation of a germ cell, and one representing learning actions focused on the concrete design of curricular units for the classroom (Fig. 5).

Looking at learning actions focused on concrete designs first, we can see that modelling is occurring throughout the process, with a dip in Session 3, where modelling actions were connected to the general conceptualization. In Sessions 4 and 5, there is a peak in examining and analysing, in line with the script as these two sessions were intended to use concrete design to examine and test the general model. In Session 6, intended to be an evaluation, there are still actions of modelling new curricular units, a sign of the ongoing design practice throughout the process. There are no acts of questioning, reflections, or consolidating associated with the concrete designs. In Session 1, there were discussions of implementation of previous curricular units, but Sessions 3 to 5 were focused on new versions and applications of the concept, which were evaluated in Session 6. There is a discernible pattern of a design cycle with analysis, modelling, examination, and implementation from Sessions 4 to 6 - an object-bound cross-session cycle.

Looking at the diagram of learning actions identified as general modelling, the cycle of expansive learning becomes clearer. The diffuse primary contradictions, experienced before the CL, were aggravated and manifested as secondary contradictions in Session 1, which was dominated by questioning and analysis. Sessions 2 and 3 were used to examine and model a concept from the representation of a possible Zone of Proximal Development. Sessions 4 and 5 were focused on concrete designs,
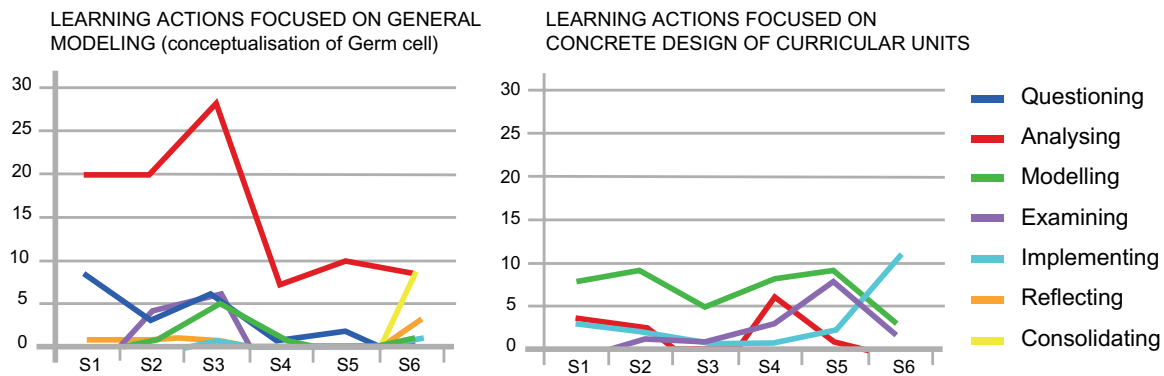

Fig. 5 Evolution of frequency of different expansive learning actions over the course of the Change Laboratory sessions, divided between general modelling and concrete design 
but there are learning acts of analysis connected to the general model present in these sessions, indicating that the concrete design actions were used to explore and analyse the conceptual level as well. Questioning connected to analysis of implemented curricular units suggests tertiary contradictions. As the object of the activity could change without larger impact on neighbouring activity systems, the absence of questioning in the final session excludes quaternary contradictions.

The presence of actions directed at concrete design throughout the process raises questions about their relationship to the general modelling and the ideal cycle of expansive learning. Cyclicity was identified in both processes, but their simultaneous occurrence challenges the succession of steps in the cycle of expansive learning. To examine this more deeply, a closer analysis of possible cyclicity at the session level is needed. As can be seen in Table 2, all the sessions contained more than the minimum of four different expansive learning actions posited to identify an expansive learning cycle (Engeström et al. 2013). A diagram of all six sessions and the evolution of learning actions can be found in "Appendix 1". The minimal criterion of four expansive learning actions in a meaningful order to identify a mini cycle of expansive learning was hard to identify in this data. The notion of meaningful order would ideally be at least four expansive learning actions of clear succession without interruptions or deviations following the general directionality of the theoretically formulated expansive cycle. Only one such cycle was found in the data. In Session 3 , a discussion of the lack of media literacy components in teacher education programmes was analysed and picked up again in the modelling and examination of the ZPD model. The successive order of learning actions was questioning $->$ analysis $->$ modelling $->$ modelling $->$ modelling $->$ examining (Episodes 36-41, see Fig. 6). This sequence was part of the succession over the entire session which went from questioning to modelling and examination in a fairly, ideal cycle (Fig. 6).

Session 3 was the only session with this clear progression. In all the other sessions there were a lot of deviations and interruptions from the ideal progression of learning actions. The criterion set up by Engeström et al. allowed for some deviation if the order of the actions is still in accordance with the directionality of the theoretical cycle (e.g. questioning -> analysis -> modelling -> questioning - > examining) (Engeström et al. 2013). For the most part, the deviations in all sessions but Session

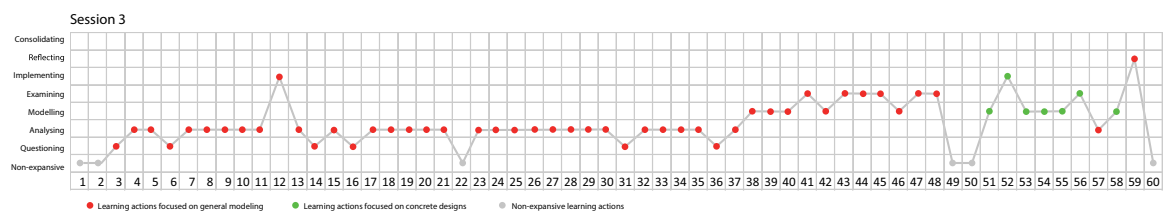

Fig. 6 Evolution of expansive learning actions over the course of session 3 
3 were greater than this. Does that mean they are not expansive? An analysis of Session 2 below tries to answer that question. Session 2 was selected due to the occurrence of six types of learning actions and the deviation from the intended script as participants came back to modelling concrete learning designs at several points in the process. A description of all episodes in Session 2 can be found in Table 4. A diagram of the evolution of learning actions can be seen in Fig. 7. The aim of Session 2 was to present the four-field model of contradictions and a Zone of Proximal Development (ZPD) as well as a general analysis of teachers' work practice. But there were deviations in the form of concrete design actions and evaluation of previous designs. Six thematic sequences were identified in the session: 1. General analysis of work practices 2. Student participation and group processes 3. Presentation, modelling, and examination of ZPD model. 4. Ideation and analysis of new curricular units 5. Analysis of challenges and complexity in new practices 6. Modelling a new international collaboration. The session ended with an episode of examining the ZPD model.

The first sequence, general analysis of work practices (Episodes 1-9) started with analytical acts on a general level, but Episode 4 was an isolated discussion about the need to be in control as a teacher that was never picked up later and therefore coded as a non-expansive learning action. In Episode 7, the teachers questioned the relevance of traditional activities in school, due to the lack of real-world connections. The researcher took this up again and started a discussion about the participating teachers' professional development during the design process. This act of questioning triggered a reflective action on media literacy, which in turn triggered an analysis of the need for video production in the teaching practice (Episode 9). This suggests that it is the content of different actions that triggers other actions rather than what type of action it is. The second sequence, Student participation and group processes, starts in Episode 10. A teacher picked up a thread from earlier reflections about the design process and had a concrete idea to let students use the same design tools as the teachers to participate in the modelling of the new curricular units. This idea was challenged by another teacher, expressing doubt about students' commitments and challenges with group processes in the classroom (Episode 11).

This triggered an analysis of previous group processes when students worked with video (Episode12), which led to practical ideas regarding ways to find solutions for the new curricular units with video production. Here, a concrete design action triggered acts of analysis, which lead to new ideas for practical solutions. The third sequence, presentation, modelling, and examination of ZPD model (Episodes 14-22) started with a presentation of the model which triggered defensive actions by the teachers. This led to analytical examination of the model (Episodes 14-16). In Episode 17, the teachers described a new curricular unit with video production that they had tested to grasp the concept of the model. This triggered analysis of the implemented task which led to the modelling of changes in the design, which in turn was used to examine the ZPD model. In this sequence, the teachers used concrete 


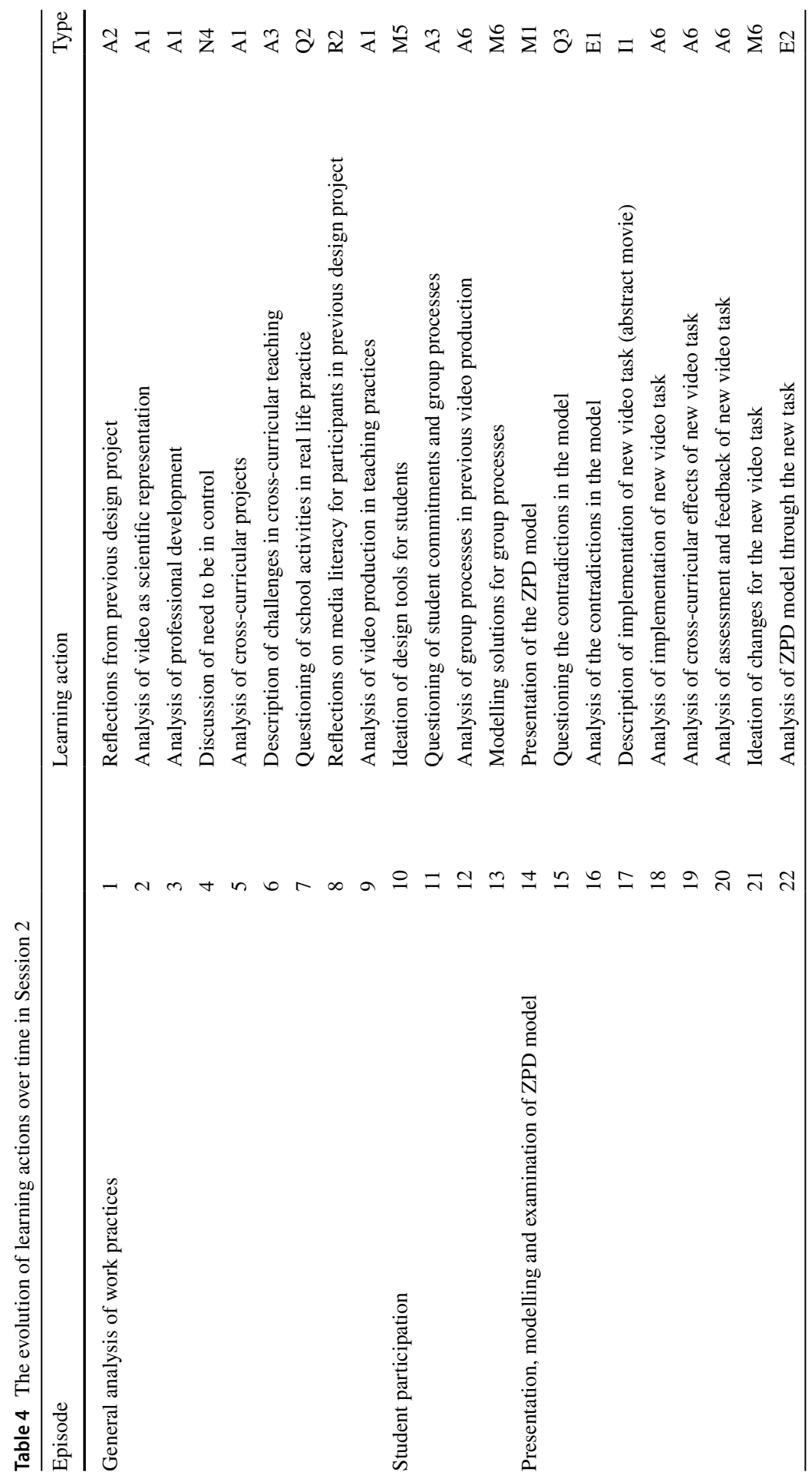




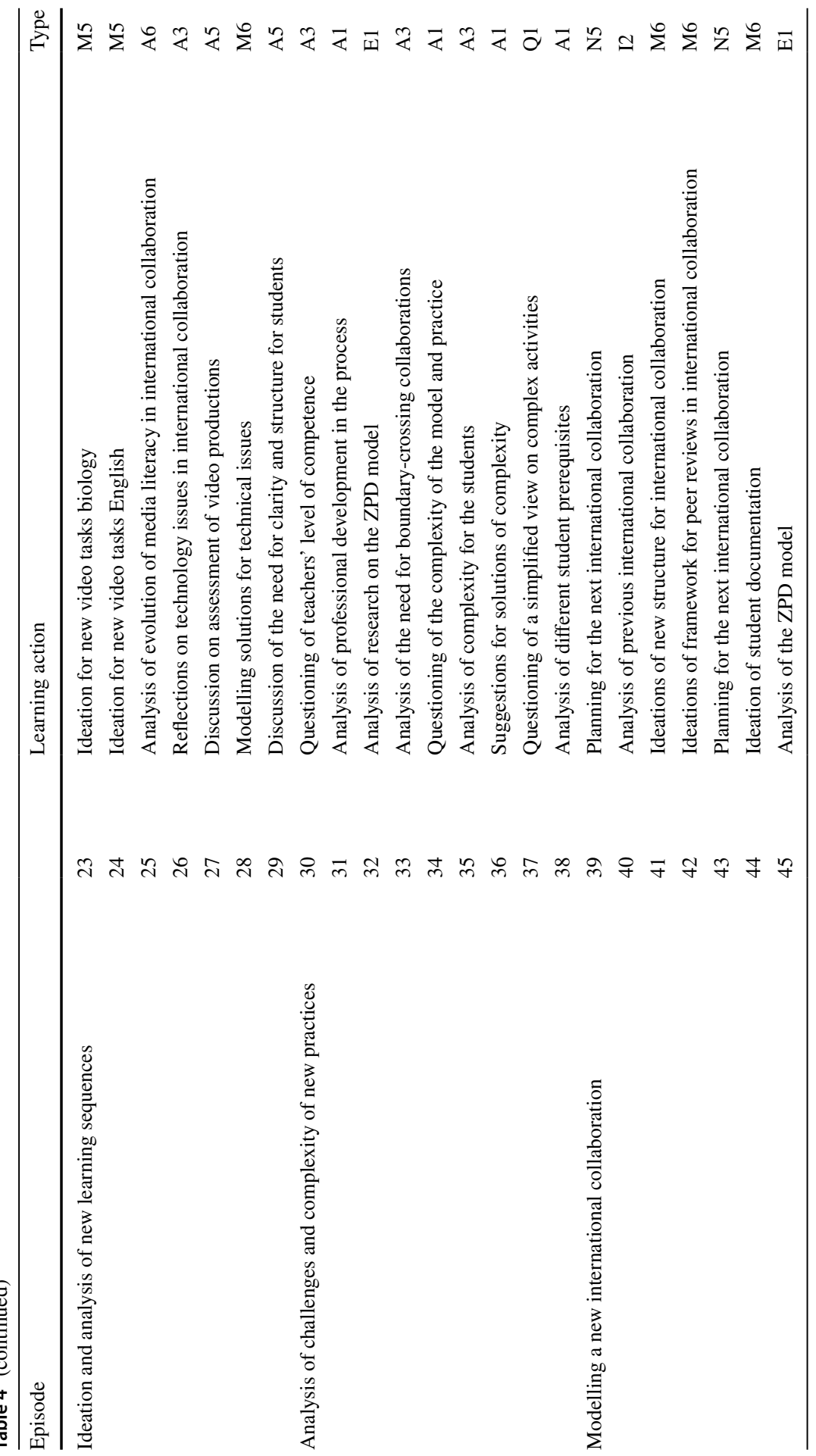




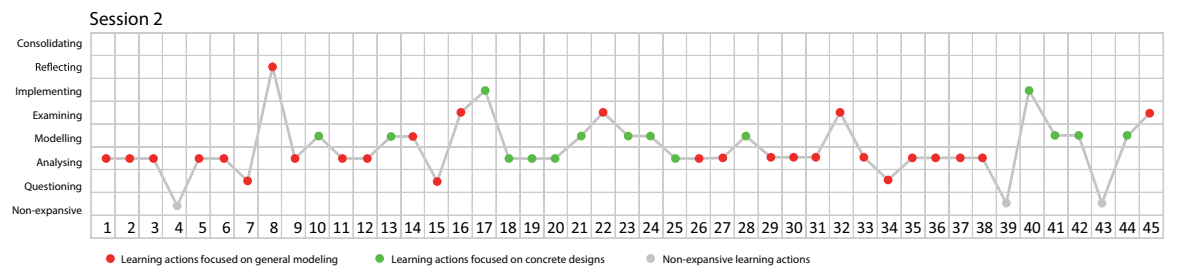

Fig. 7 The evolution of learning actions over time in Session 2

designs to understand and then explore the abstract model. The process was not linear, but dialectic, as it moved back and forth between 'the abstract and the concrete', challenging a purist notion of ascension. The fourth sequence, ideation and analysis of new learning sequences (Episodes 23-29), started with the ideation of two new curricular units with video productions that could be used before the planned international collaboration, which triggered a general discussion on media literacy development, technological issues, assessment, and possible solutions. In this sequence there was also back and forth movement between concrete design and general analysis. The fifth sequence, analysis of challenges and complexity in new practices (Episodes $30-38$ ), started with an articulation of the need for improved media literacy competence for the teachers, which triggered a sequence of analytical actions. In Episode 32, a description of research results critical to media production was used to examine the ZPD model. In Episode 34, a teacher questioned the need for this complex model and analytical process stating that this made things more complicated than necessary, which triggered acts of analysis ending in agreement about the complexity and the need to address the challenges properly. In this sequence there is a reversed cycle in which an examination of the model resulted in analysis that led to questioning. Despite this, it triggered acts of analysis and development of the process. The sixth sequence, modelling a new international collaboration, started with the need for teachers to discuss the practical planning of the next international collaboration. This action was coded as a non-expansive learning action, but nonetheless it triggered a sequence of analysis and remodelling of the design for the international collaboration, interrupted by another episode of practical planning. This suggests that even a non-expansive action of practical planning and scheduling can trigger a sequence of expansive learning actions challenging the dichotomy and boundaries between them. Session 2 ended with a summarizing examination of the ZPD model, prompted by the researcher. The session was full of deviations and movement back and forth between different learning actions and between concrete design and analysis. Despite this entanglement and lack of cyclicity, both concrete designs and conceptual models were developed and moved forward. 


\section{Conclusions and discussion}

The CL intervention enabled teachers to analyse and reflect on their work practice as well as to change it and design new innovative learning tasks for their students. All seven learning actions proposed in the theory of expansive learning were identified in this study, but they were interspersed with odd combinations and deviations. The theory of expansive learning is dependent on dialectical movement between learning actions. Non-expansive learning in this study is interpreted as isolated learning actions that don't trigger other learning actions or push the process forward. This includes types of actions that have the possibility of being expansive but are not taken up later in the process. A conclusion drawn from this is that expansive movement is not inherent in the different epistemic actions themselves, but in the relation between them. Non-expansive learning actions as categorized by Engeström et al. (2013) can be triggers for development of other learning actions as observed in the practical planning of a new international collaboration in Session 2. As such, these actions are vital to the process and challenge the boundary and dichotomy between expansive and non-expansive learning actions. The entanglement of practical design actions within the CL sessions called for the creation of subtypes of learning actions to separate the two processes. This was not an easy task since they were connected to each other and shared epistemic functions. The categories are not fixed or stable and rely heavily on the interpretations of the researcher. But even if some learning actions were to be interpreted and categorized differently, it wouldn't change the overall analysis of cyclicity. The planned intervention upheld the overarching cycle of expansive learning even if it was disrupted by practical design activity throughout the sessions. The vital actions of questioning and analysis at a systemic level connected the design process to the activity system, addressing contradictions and tensions that it was crucial to resolve for a successful implementation and development. Likewise, actions of modelling concrete designs triggered analysis and modelling of the general model. At the session level, there were few examples of linear evolution or cyclicity of learning actions and many disruptions of practical design and movements back and forth. This suggests that cyclicity might be desirable, but is not necessary, for expansive learning and that it challenges the notion of ascension and the need to first grasp the problem at a conceptual level before generating concrete solutions. The findings in this study suggest the opposite: that the entanglement and movement between the abstract and the concrete was a driving force for the teachers' expansive learning and the creation of new curricular units. The identification of the seven expansive learning actions functioned as tools to map and analyse this process. To see one type of learning action as a trigger or stimulus for another type of learning action could be a way to analyse expansive learning without being locked into finding whole, disrupted or non-existing cycles which could limit the analysis. Instead, the analysis would create a map of interconnecting learning actions that show different, contextual landscapes of learning, expanding as the process continues. The paths and turns on these maps are held together by the script of the intervention securing the overarching cycle of expansive learning. 
The timescale of this CL is spread out over 18 months, which differs from many CL interventions with six to eight frequent, regular sessions. The main reason for this was the aim to have the whole process of the change effort inside the process to let implementation and consolidation be part of the intervention. This is seldom possible in a CL conducted over a short time span (like Engeström et al. 2013). If the CL methodology aims to cover all the posited expansive learning actions, it needs to be spread out over a longer period of time with final sessions after the implementation of new models. During a longer timeframe, participants have more time in between sessions to reflect on the process and develop their practice. Therefore, their input in the sessions might challenge the script and be more focused on concrete solutions. This could be one explanation for the high frequency of odd combinations and deviations from learning actions in this study, but does not change the conclusion that despite this, expansive learning occurred inside the sessions. The highly situated circumstances in this intervention, as a response to challenges in a design process with a small group of teachers, could also affect the process and results in a similar way. But the overarching evolution of the expansive learning cycle was identified despite (or because of) the large number of odd combinations of learning actions. In the end, the most persuasive evidence of expansive learning in a CL is if the new practice and changes in the teacher's activity system are stable and continuously evolving over time, after the enacted intervention. Making implementation and consolidation part of the CL ensures the exploration of this.

Funding Open access funding provided by University West.

\section{Compliance with ethical standards}

Conflict of interest The author declares that he has no conflict of interest.

Informed consent All participants in this study have signed an informed consent.

Open Access This article is licensed under a Creative Commons Attribution 4.0 International License, which permits use, sharing, adaptation, distribution and reproduction in any medium or format, as long as you give appropriate credit to the original author(s) and the source, provide a link to the Creative Commons licence, and indicate if changes were made. The images or other third party material in this article are included in the article's Creative Commons licence, unless indicated otherwise in a credit line to the material. If material is not included in the article's Creative Commons licence and your intended use is not permitted by statutory regulation or exceeds the permitted use, you will need to obtain permission directly from the copyright holder. To view a copy of this licence, visit http://creativecommons.org/licen ses/by/4.0/.

\section{Appendix 1}

See Fig. 8 . 


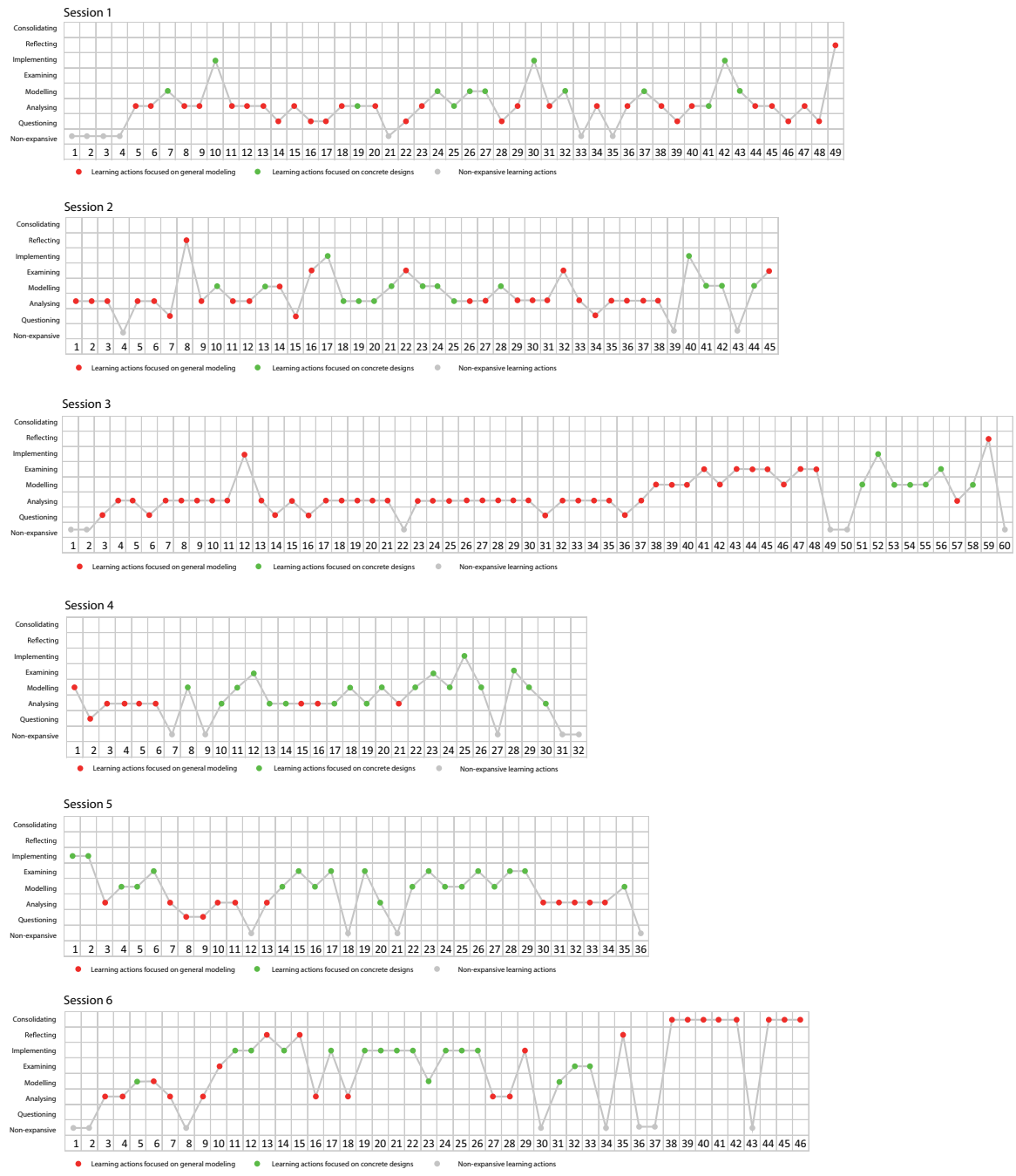

Fig. 8 The evolution of learning actions at the session level

\section{References}

Augustsson, D. (2018). Collaborative media in educational settings: Teaching as a design profession. The International Journal of Design Education, 13(2), 1-19.

Bal, A., Afacan, K., \& Cakir, H. I. (2018). Culturally responsive school discipline: Implementing learning lab at a high school for systemic transformation. American Educational Research Journal, 55(5), $1007-1050$

Botha, L. (2017). Changing educational traditions with the change laboratory. Education as Change, 21(1), 73-94. https://doi.org/10.17159/1947-9417/2017/861.

Davydov, V. V. (1990). Types of generalization in instruction: Logical and psychological problems in the structuring of school curricula. Reston: National Council of Teachers of Mathematics. 
Engeström, Y. (2008). Weaving the texture of school change. Journal of Educational Change, 9(4), 379-383.

Engeström, Y. (2015). Learning by expanding: An activity-theoretical approach to developmental research (2nd ed.). Cambridge: Cambridge University Press.

Engeström, Y., Engeström, R., \& Suntio, A. (2002). Can a school community learn to master its own future? An activity-theoretical study of expansive learning among middle school teachers. In G. Wells \& G. Claxton (Eds.), Learning for life in the 21st century: Sociocultural perspectives on the future of education. Oxford: Blackwell.

Engeström, Y., Nummijoki, J., \& Sannino, A. (2012). Embodied germ cell at work: Building an expansive concept of physical mobility in home care. Mind, Culture, and Activity, 19(3), 287-309. https://doi. org/10.1080/10749039.2012.688177.

Engeström, Y., Rantavuori, J., \& Kerosuo, H. (2013). Expansive learning in a library: Actions, cycles and deviations from instructional intentions. Vocations and Learning, 6, 81-106.

Engeström, Y., \& Sannino, A. (2010). Studies of expansive learning; foundations, findings and further challenges. Educational Research Review, 5, 1-24.

Englund, C. (2018). Exploring interdisciplinary academic development: The Change Laboratory as an approach to team-based practice. Higher Education Research \& Development, 37(4), 698-714. https ://doi.org/10.1080/07294360.2018.1441809.

European Commission. (2013). DIGCOMP: A Framework for Developing and Understanding Digital Competence in Europe. JRC Scientific and Policy Reports JRC83167. https://doi.org/10.2788/52966

Leont'ev, A. N. (1978). Activity, consciousness, and personality. Englewood Cliffs: Prentice-Hall.

Sannino, A. (2008). Sustaining a non-dominant activity in school: Only a utopia? Journal of Educational Change, 9(4), 329-338.

Sannino, A. (2015). The principle of double stimulation: A path to volitional action. Learning Culture and Social Interaction, 6, 1-15.

Sannino, A., \& Engeström, Y. (2017). Co-generation of societally impactful knowledge in change laboratories. Management Learning, 48(1), 80-96.

Sannino, A., Engeström, Y., \& Lemos, M. (2016). Formative interventions for expansive learning and transformative agency. Journal of the Learning Sciences., 25(4), 599-633. https://doi. org/10.1080/10508406.2016.1204547.

Teräs, M., \& Lasonen, J. (2013). The development of teachers' intercultural competence using a change laboratory method. Vocations and Learning, 6, 107-134.

Trilling, B., \& Fadel, C. (2009). 21st century skills-Learning for life in our times. San Francisco: Jossey-Bass.

UNESCO (2011). Media and information literacy curriculum for teachers. Retrieved at: https://unesd oc.unesco.org/ark:/48223/pf0000192971_eng

Virkkunen, J., \& Schaupp, M. (2011). From change to development: Expanding the concept of intervention. Theory and Psychology, 21(5), 629-655.

Vygotsky, L. S. (1987). The collected works of L.S. Vygotsky: Problems of general psychology. New York: Plenum Press.

Yamazumi, K. (2008). A hybrid activity system as educational innovation. Journal of Educational Change, 9(4), 365-373.

Publisher's Note Springer Nature remains neutral with regard to jurisdictional claims in published maps and institutional affiliations. 